\title{
Development of tuberculin reactivity and sensitization to $M$. Scrofulaceum and M. Fortuitum in children BCG-vaccinated at birth
}

\author{
L. Kröger*, M. Korppi*, J. Pelkonen**, M. Pietikäinen+, M.L. Katila**
}

Development of tuberculin reactivity and sensitization to $\mathrm{M}$. Scrofulaceum and $\mathrm{M}$. Fortuitum in children BCG-vaccinated at birth. L. Kröger, M. Korppi, J. Pelkonen, M. Pietikäinen, M.L. Katila. C) ERS Journals Ltd 2000.

ABSTRACT: Since the incidence of tuberculosis is steadily declining in Finland and infections by environmental mycobacteria may be increasing, the aim of the present study was to evaluate the development of tuberculin reactivity and sensitization to environmental mycobacteria.

Healthy Finnish schoolchildren aged 10.4-12.4 yrs $(\mathrm{n}=201)$ were tested with tuberculin purified protein derivative RT23, Mycobacterium scrofulaceum RS95 and $M$. fortuitum RS20 sensitins. The same children had been previously tested with the same antigens and methods at the age of 4-6 yrs in 1989. Rapid waning of tuberculin reactivity and decrease in sensitization to environmental mycobacteria were observed between 4-6 yrs.

Both tuberculin and sensitin skin reaction sizes decreased significantly over the 6yrs period. The mean tuberculin skin reaction size was $3.2 \mathrm{~mm}$ in diameter, which was significantly $(p<0.001)$ smaller than the mean induration size $(4.8 \mathrm{~mm})$ at the age of 4 6 yrs. Similarly, the mean skin reaction sizes to $M$. scrofulaceum and $M$. fortuitum sensitins were 3.4 and $1.7 \mathrm{~mm}$, respectively, which were significantly $(p<0.001)$ smaller than 6 yrs earlier (mean 4.5 and $3.1 \mathrm{~mm}$ ). The number of zero reactions to all antigens increased significantly during the follow-up period. Contacts with pets or farm animals were associated with larger reactions. In contrast, children suffering from allergic symptoms had smaller reactions.

Contacts with mycobacteria, either with Mycobacterium tuberculosis or environmental mycobacteria, seem to be too rare to maintain tuberculin responsiveness and a high sensitivity to other mycobacteria. Different bacille Calmette-Guérin vaccine products and dosages used, the declining incidence of tuberculosis and geographical factors, which can influence environmental mycobacterial exposure, may explain the disparity between the present and previous Finnish studies. Eur Respir J 2000; 15: 382-387.
*Dept of Paediatrics, Kuopio University Hospital, Kuopio, Finland. **Depts of Clinical Microbiology, Kuopio University and Kuopio University Hospital; ${ }^{+}$Public Health Centre, Sillinjärvi, Finland.

Correspondence: L. Kröger

Dept of Paediatrics

Kuopio University Hospital

FIN-70 211 Kuopio

Finland

Fax: 35817172410

Keywords: Bacille Calmette-Guérin children

environmental mycobacteria

sensitin

tuberculin

Received: February 221999

Accepted after revision September 61999

This study was supported by the Finnish Lung and Health Association and the Maud Kuistila Foundation.
As a result of effective tuberculosis control measures, the incidence of pulmonary tuberculosis has steadily declined in Finland. In 1996, it was estimated to be only 8.4 per 100,000 population [1]. In contrast to in many other parts of the world, the new cases of tuberculosis have been concentrated in the oldest, non-bacille CalmetteGuérin (BCG)-vaccinated, age groups $[1,2]$. In addition, the incidence of human immunodeficiency virus (HIV) is low and HIV infections have been very rare in young infants and children (no reported cases in 1996) [1]. Since the 1950s, BCG vaccination has been routinely offered to all newborn babies, and the vaccination coverage has been invariably close to $100 \%$ [3].

Environmental mycobacteria, though low in virulence, may cause suppurative cervical adenitis in healthy children at an early age [4]. Although these infections are rare, there is evidence suggesting that their incidence is increasing throughout the world [5-7]. Sensitization to environmental mycobacteria in non-BCG-vaccinated child populations measured by skin testing seems also to be increasing [8]. These data indicate an increase in environmental exposure to mycobacteria $[8,9]$. Although previous studies have suggested that sensitization increases with age, the incidence of mycobacterioses due to environmental mycobacteria in children is highest at the age of $1-6$ yrs $[4,10,11]$. There is also evidence that sensitization may vary according to geographical location, even within a small country [12-14].

In an earlier cross-sectional study, a rapid decrease in tuberculin reactivity occurring between the ages of 4 and 6 yrs was observed [15]. The sensitization to nontuberculous mycobacteria seemed to be common but also decreased with age [16]. Previous Finnish studies have generally shown higher tuberculin reactivity and higher sensitivity to Mycobacterium scrofulaceum in children at the age of $10-13$ yrs $[17,18]$. The aim of the present study was to examine tuberculin reactivity and follow the degree of sensitization to environmental mycobacteria in a group of BCG-vaccinated children living in the same geographical region during a 6-yr follow-up period. 


\section{Subjects and methods}

\section{Subjects}

In April 1989, all children born in 1983-1984 and living in a defined area of the municipality of Siilinjärvi, Finland, were invited to take part in a study on tuberculin skin test reactivity and sensitization to environmental mycobacteria. It included skin testing with mycobacterial antigens, a questionnaire filled in by the parents and a medical examination. Of the 434 invited children, 353 participated in the initial study $[15,16]$. The children were healthy and, according to the medical records, all had been vaccinated as newborns with the Glaxo BCG vaccine (Glaxo Laboratories Ltd, Greenford, Middlesex, UK) at a dose of $0.05 \mathrm{~mL}$.

Six years later, in May 1995, a follow-up study was undertaken with the purpose of examining the same children again. During the 6-yr period, 70 children had moved away from the Siilinjärvi area. A further 77 children either refused, were acutely ill during the time of testing or were otherwise inaccessible. Thus, the final number of children retested was 205 .

The Ethics Committee of Kuopio University Hospital approved the study. A letter was sent to the parents explaining the reason for the study and testing was only performed if the parents had provided written informed consent.

\section{Skin tests}

In 1989, the test antigens used were tuberculin purified protein derivative (PPD) RT23, M. avium sensitin RS10, $M$. scrofulaceum sensitin RS95 and $M$. fortuitum sensitin RS20. Owing to the high cost of the antigens, the number of antigens was reduced to three in the retesting. M. avium was omitted and M. scrofulaceum was chosen to represent slowly growing environmental mycobacteria, because it had been widely used in other similar studies $[9,12,13,18$, 19]. In the initial study, the skin test results were rather similar with M. avium and M. scrofulaceum antigens [16]. $M$. fortuitum was included as a representative of rapidly growing species commonly present in the environment, that are potentially pathogenic to man [20]. The sensitins $(0.1 \mathrm{~mL})$ were used at a dilution of $1 \mu \mathrm{g} \cdot \mathrm{mL}^{-1}$ and 2 tuberculin units (TU) tuberculin PPD RT 23 were administered. The antigens were obtained from the Statens Serum Institut (Copenhagen, Denmark). The Mantoux technique was performed according to the World Health Organization (WHO) recommendations [21]. All three injections were performed concomitantly on the dorsal aspects of the forearms, two on the left and one on the right. All test injections as well as the reading of the reactions after 3 days were performed by the same personnel as in the previous study. The skin test results were measured by recording the transverse diameter of the induration in millimetres. The test antigens were coded and the code was broken after measuring the skin test results.

\section{Questionnaire}

The parents filled in a questionnaire, which contained questions about contacts with persons with tuberculosis, previous tuberculin testing, chronic diseases such as asthma or allergies, long-term medications and contacts with pets and farm animals. Recent use of antihistamines and topical corticosteroids were also recorded. The questionnaire was checked by the test personnel at the time of the testing.

\section{Statistical methods}

Statistical analysis was performed using SPSS for Windows 8.01 software (SPSS, Chicago, IL, USA). The nonparametric Mann-Whitney U-test, Wilcoxon matched-pair signed-rank test and Chi-squared test were used. A p-value of $<0.05$ was considered significant.

\section{Results}

The number of children retested was 205. Since four children were absent from the reading due to an acute illness, the final number was 201 (100 females and 101 males). The mean age of the children was 11.3 yrs (range 10.4-12.4 yrs). The mean diameter of the induration to tuberculin PPD RT23 was $3.2 \mathrm{~mm}$ (range $0-28 \mathrm{~mm}$ ), to $M$. scrofulaceum $3.4 \mathrm{~mm}$ (range $0-26 \mathrm{~mm}$ ) and to $M$. fortuitum $1.7 \mathrm{~mm}$ (range $0-14 \mathrm{~mm}$ ) (fig. 1). The age of the child had no influence on mean skin reaction sizes. Tuberculin reaction sizes were slightly smaller in females $(2.9 \mathrm{~mm})$ than in males $(3.5 \mathrm{~mm})$. Conversely, reactions to $M$. fortuitum sensitin were larger in females than in males (2.0 versus $1.4 \mathrm{~mm}, \mathrm{p}<0.05)$ (Table 1$)$.

None of the children showed any clinical manifestation of a mycobacteriosis. No cases of tuberculosis had been diagnosed among the study group during the follow-up period. Seven children had been in tuberculosis contact and therefore had also been tested for tuberculin reactivity. In all cases, the testing had been done $>1$ yrs prior to the present study. There was no difference in their skin test reactivity compared to the other children.

There were 74 children with a $0 \mathrm{~mm}$ reaction to tuberculin. If there was a zero reaction to tuberculin, the mean reaction sizes to the two sensitins were also small: $1.1 \mathrm{~mm}$ to $M$. fortuitum and $1.3 \mathrm{~mm}$ to $M$. scrofulaceum sensitin. In this group, only five $(6 \%)$ children showed a positive $(\geq 5$ $\mathrm{mm}$ ) reaction to $M$. scrofulaceum sensitin and only three (4\%) to M. fortuitum sensitin, all of whom expressed strong positive ( $\geq 10 \mathrm{~mm}$ ) skin reactions.

When compared with the results from the initial study in 1989 , the average diameter of reaction sizes to tuberculin and both sensitins had decreased. At the age of 4-6 yrs, the mean skin reaction sizes to tuberculin PPD and $M$. scrofulaceum and $M$. fortuitum sensitins were $4.8 \mathrm{~mm}, 4.5$ $\mathrm{mm}$ and $3.1 \mathrm{~mm}$, respectively. Six years later, at the age of $10-12 \mathrm{yrs}$, the values were significantly $(\mathrm{p}<0.01)$ smaller, i.e. $3.2 \mathrm{~mm}, 3.4 \mathrm{~mm}$ and $1.7 \mathrm{~mm}$, respectively. Subgroup analysis revealed that, in children initially $<5.5$ yrs old, the decrease in mean reaction size was significant $(\mathrm{p}<0.05)$ but no change was found in children initially $>5.5$ yrs (fig. 2 ). The proportion of children with zero skin test reaction sizes increased significantly between the baseline and the follow-up studies. The mean reaction sizes in children with skin reactions of $\geq 1 \mathrm{~mm}$ were also significantly smaller at the follow-up survey (table 2). 

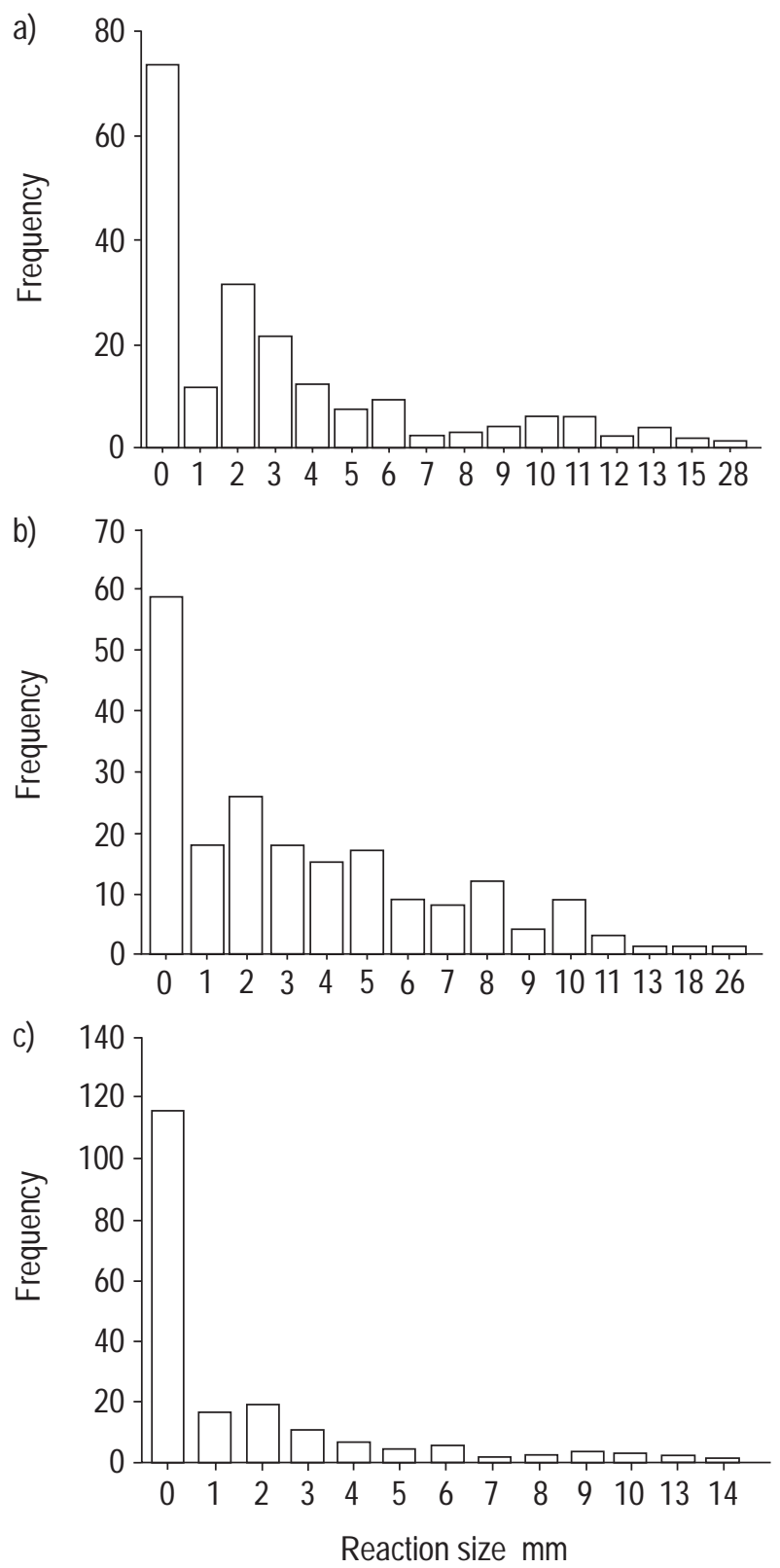

Fig. 1. - Frequencies of the different skin reaction sizes to a) tuberculin; and b) Mycobacterium scrofulaceum; and c) M. fortuitum sensitins.

Twelve $(6 \%)$ children expressed an increase in reaction size to $M$. scrofulaceum and eight (4\%) to $M$. fortuitum sensitin, the greatest increase being $12 \mathrm{~mm}$. In eight children, tuberculin reaction size was $\geq 4 \mathrm{~mm}$ greater than at baseline, the greatest difference being $13 \mathrm{~mm}$. None of the children who previously gave negative skin test reactions and who subsequently gave positive tuberculin reactions showed any clinical sign of tuberculosis.

Allergic diseases and the use of antihistamines were associated with lower tuberculin and sensitin reactivity. In children suffering from allergic diseases, the mean tuberculin induration size was smaller $(2.5 \mathrm{~mm})$ than in nonallergic children $(3.4 \mathrm{~mm})$, but the difference was not statistically significant. The reactions to $M$. scrofulaceum sensitin were significantly $(\mathrm{p}<0.05)$ smaller in children with allergic disorders $(2.5 \mathrm{~mm}$ versus $3.8 \mathrm{~mm})$. The same tendency was observed in reactions to $M$. fortuitum sensitin, although the differences were not statistically significant (table 1).

In contrast, contact with pets or farm animals was associated with larger reactions to tuberculin and sensitins (table 1). As many as 151 (74\%) children had pets at home, and $16(8 \%)$ were living on a farm. The mean skin reaction sizes in children with pets at home were $3.5 \mathrm{~mm}$ to tuberculin, $3.8 \mathrm{~mm}$ to M. scrofulaceum sensitin and 1.9 $\mathrm{mm}$ to $M$. fortuitum sensitin, which were significantly larger than in children without contacts with animals. In children living on a farm $(\mathrm{n}=16)$, mean skin reaction sizes to tuberculin and M. scrofulaceum and M. fortuitum sensitins were 3.9, 5.2 and $1.8 \mathrm{~mm}$, respectively. The reactions to M. fortuitum sensitin were significantly $(\mathrm{p}<0.05)$ larger in children living on a farm.

Sixty-four of the children had been given a booster polio vaccine (Salk) during the preceding 4 months (according to the Finnish vaccination programme). There were no significant differences between revaccinated and nonrevaccinated groups in reaction sizes (table 1).

\section{Discussion}

No follow-up studies on tuberculin reactivity have previously been carried out in Finnish children. Earlier cross-sectional studies have indicated an increase in tuberculin reactivity from early childhood to adolescence. A study in the $1970 \mathrm{~s}$, performed in children aged 3 months, 11-12 yrs and 18-19 yrs, showed reaction sizes of 6.8, 6.9 and $9.2 \mathrm{~mm}$, respectively [17]. In a more recent study, performed in children 11-13 yrs of age, the mean tuberculin reaction size was $8.2 \mathrm{~mm}$ [18]. Compared to these earlier Finnish studies, the present study in 4-6-yr-old children revealed an unexpectedly small mean induration size $(4.8 \mathrm{~mm})$ with a significant age-related decline from 4-6 yrs [15]. Six years later, the same children yielded only half of the mean reaction size of those studied in the earlier Finnish study of children of the same age [18]. Thus the present results were unexpected.

As far as the authors are aware, earlier studies on sensitization to environmental mycobacteria have all been cross-sectional. In the present study, the same children were prospectively followed for changes in their reactivity to mycobacterial antigens. Only children living continuously in the same community were included in the testing to avoid the potential confounding effect caused by change of environment, which is the likeliest source of exposure to environmental mycobacteria [22]. The initial study showed a decrease in mycobacterial sensitization with increasing age from 4 to 6 yrs [16]. An earlier Finnish study on mycobacterial sensitivity in BCG-vaccinated children aged 11-13 yrs had shown significantly larger skin test reaction sizes than detected in the authors' initial study [17]. It was therefore expected that there would be an increase in reactions size as the children aged from 6 yrs to 11-13 yrs of age. However, this was not the case. In fact, a further decrease in mean skin reaction sizes and an increase in the number of zero reactions were observed.

It has been postulated that tuberculin sensitivity may wane more rapidly in children to whom BCG vaccination was given shortly after birth compared to those in whom 
Table 1. - Mean tuberculin and sensitin reaction size in subgroups according to sex, allergic disease, use of antihistamines or topical corticosteroids and recent polio vaccination

\begin{tabular}{|c|c|c|c|c|}
\hline & \multirow{2}{*}{$\begin{array}{c}\text { Subjects } \\
\mathrm{n}\end{array}$} & \multicolumn{3}{|c|}{ Reaction size $\mathrm{mm}$} \\
\hline & & Tuberculin & Mycobacterium scrofulaceum & Mycobacterium fortuitum \\
\hline \multicolumn{5}{|l|}{ Sex } \\
\hline Male & 101 & $3.5 \pm 0.4$ & $3.4 \pm 0.4$ & $1.4 \pm 0.2^{+}$ \\
\hline Female & 100 & $2.9 \pm 0.4$ & $3.5 \pm 0.4$ & $2.0 \pm 0.3$ \\
\hline \multicolumn{5}{|l|}{ Allergy } \\
\hline Allergic symptoms & 57 & $2.5 \pm 0.4$ & $2.5 \pm 0.4^{\#}$ & $1.4 \pm 0.4$ \\
\hline No allergy & 144 & $3.4 \pm 0.4$ & $3.8 \pm 0.3$ & $1.8 \pm 0.2$ \\
\hline Peroral antihistamines & 15 & $2.1 \pm 0.6$ & $2.1 \pm 0.6$ & $0.9 \pm 0.4$ \\
\hline Topical corticosteroids & 13 & $2.0 \pm 0.8$ & $3.0 \pm 0.8$ & $1.9 \pm 0.7$ \\
\hline \multicolumn{5}{|l|}{ Animal contacts } \\
\hline Pets at home & 151 & $3.5 \pm 0.3 * * *$ & $3.8 \pm 0.3$ & $1.9 \pm 0.2 * * *$ \\
\hline Contact with farm animals & 16 & $3.9 \pm 0.3$ & $5.2 \pm 1.1$ & $1.8 \pm 0.7 *$ \\
\hline No pets/farm animals & 48 & $2.4 \pm 0.7$ & $2.3 \pm 0.6$ & $1.0 \pm 0.2$ \\
\hline \multicolumn{5}{|l|}{ Polio vaccine } \\
\hline Revaccinated & 64 & $2.7 \pm 0.4$ & $3.0 \pm 0.4$ & $1.7 \pm 0.4$ \\
\hline Nonrevaccinated & 137 & $3.3 \pm 0.4$ & $3.6 \pm 0.3$ & $1.7 \pm 0.4$ \\
\hline
\end{tabular}

Data are presented as mean \pm SEM. ${ }^{+}: \mathrm{p}<0.05$ compared to females. ${ }^{*}: \mathrm{p}<0.05$ compared with children with no allergic symptoms; *: $\mathrm{p}<0.05 ; * *: \mathrm{p}<0.001 ;{ }^{*} \mathrm{p}<0.0001$ compared with children with no contacts with pets or farm animals.

vaccination was given at a later age [23-25]. The policy of vaccinating newborns has remained unaltered in Finland since the early 1950 s and in this respect, the present and previously examined child populations are identical. Although both child cohorts were BCG-vaccinated at birth, children in the earlier Finnish studies had received a different BCG vaccine at a higher dose $(0.1 \mathrm{~mL})$, which also caused more post-vaccination complications [26]. In contrast, the present cohort had been vaccinated with the Glaxo BCG vaccine, which replaced earlier vaccines made from the Swedish BCG strain Gothenburg, and at half of the previous dosage $(0.05 \mathrm{~mL})$ [26]. Another possible explanation for the decrease in tuberculin reaction size is the steadily decreasing tuberculosis morbidity in Finland. Tuberculosis incidence has declined from 53.6-49.2 per 100,000 population in the 1970 s to 13 per 100,000 population in 1996 [2,3]. Thus, the present child population has less frequently been at risk of natural exposure to $M$. tuberculosis than the children from the 1970s.

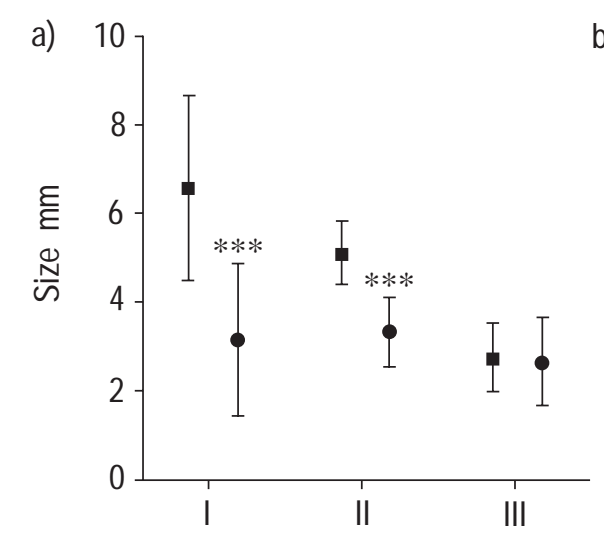

Age group
There can be wide geographical variation in the occurrence of environmental mycobacteria. A recent Finnish study revealed that the occurrence of mycobacteria in water and soils varies geographically and shows significant correlations with environmental factors such as $\mathrm{pH}$ and concentrations of metals and minerals in surface water [27]. Similarly, environmental studies in different countries as well as studies concerning sensitin skin test reactivity in children in Sweden, Norway and Greece have indicated that exposure to environmental mycobacteria varies according to geographical location [12, 13, 28, 29]. In Sweden, sensitization was significantly lower in children living in rural inland areas compared to those living in urban areas in the coastal region $[12,13]$. The present study area was an inland lake area with partly urban and partly rural conditions/environment. In contrast, the earlier Finnish study cohort demonstrating higher levels of sensitization was conducted in the western coastal region, $500 \mathrm{~km}$ from the present study area. The authors believe that this is another important factor, potentially

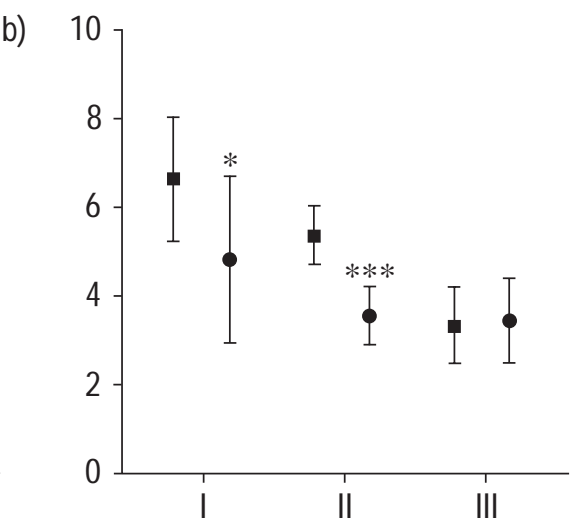

Age group

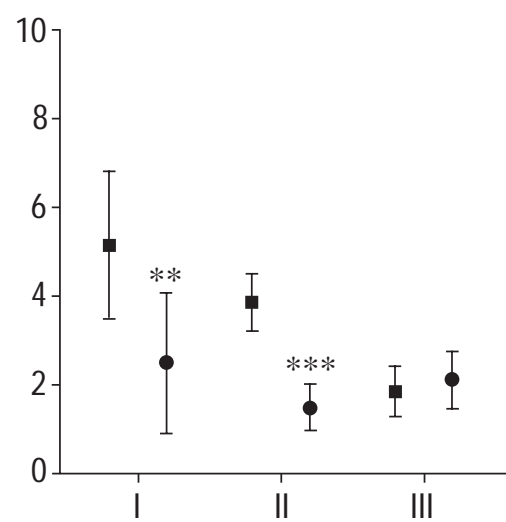

Age group

Fig. 2. - Mean skin reaction sizes to a) tuberculin; and b) Mycobacterium scrofulaceum; and c) M. fortuitum sensitins at baseline ( $\square$ ) and at follow-up $(\bullet)$ in the baseline age groups of $<4.5$ yrs (I), $4.5-5.5$ yrs (II) and $>5.5$ yrs (III). Data are presented as mean \pm SD. $*: p<0.05 ; * *: p<0.01 ; * * *: p<0.001$ between baseline and follow-up reaction sizes. (Wilcoxon sigened-rank test). 
Table 2. - Proportion of children with zero reactions to tuberculin and Mycobacterium scrofulaceum and $M$. fortuitum sensitins at the age of 4-6 yrs (baseline) and at the age of 10-12 yrs (follow-up) and mean skin reaction sizes among subjects with reaction sizes of $\geq 1 \mathrm{~mm}$

Baseline Follow-up p-value*

\begin{tabular}{lccr}
\hline Tuberculin & & & \\
0-mm reaction size \% & 21.1 & 36.2 & $<0.001$ \\
Reaction size ( $\geq 1 \mathrm{~mm}) \mathrm{mm}$ & $5.7 \pm 0.3$ & $3.8 \pm 0.3$ & $<0.001$ \\
$\begin{array}{lccr}\text { M. scrofulaceum } \\
\text { 0-mm reaction size \% }\end{array}$ & 22.0 & 29.5 & 0.009 \\
Reaction size ( $\geq 1 \mathrm{~mm}) \mathrm{mm}$ & $5.7 \pm 0.2$ & $3.9 \pm 0.3$ & $<0.001$ \\
$\begin{array}{lccr}\text { M. fortuitum } \\
\text { 0-mm reaction size \% }\end{array}$ & 34.7 & 57.8 & 0.014 \\
Reaction size ( $\geq 1 \mathrm{~mm}) \mathrm{mm}$ & $4.7 \pm 0.3$ & $2.2 \pm 0.3$ & $<0.001$ \\
\hline
\end{tabular}

Data are presented as mean \pm SEM or percentage. *: Chi-squared or Wilcoxon rank test.

accounting for the discrepancy in results between these two Finnish studies.

The antigens and techniques of testing could have been potential sources of discrepant results between the present and the earlier Finnish study (M. Tala-Heikkilä group) [18]. However, the manufacturer of the antigens and the Mantoux technique used were the same. In addition, the test personnel, who were the same in both parts of the present study were initially trained by the group of $\mathrm{M}$. Tala Heikkilä. There has, however, been discussion regarding the possible loss of potency of tuberculin PPD over the years since it was prepared in 1958 [30]. However, skin test reactivity is influenced by many simultaneously occurring factors whose true nature is difficult to analyse.

It is well known that genetic factors play an important role in responses to BCG vaccination, manifest both in skin-test results and protection against mycobacterial infections $[31,32]$. This explanation does not apply to the examined child population because the same children were re-examined after a 6-yr interval. Genetically, this child population was also similar to the populations examined in earlier Finnish studies, of the same nationality and therefore with a very similar genetic background [1518].

Allergic symptoms are relatively common in children. In this study population, 58 (28\%) children had either asthma, allergic rhinitis or dermatitis, which was approximately the same proportion as reported in a recent Finnish epidemiological study of children aged 13-14 yrs (34\%) [33]. In a Japanese study, a strong inverse relationship between tuberculin responses and atopic symptoms was found and it was suggested that exposure to $M$. tuberculosis might inhibit atopic disorders [34]. However, early BCG vaccination does not seem to affect the development of atopic diseases [35]. It has been suggested that persons suffering from allergic diseases may have smaller tuberculin reactions [36]. As in the authors' study, children with allergic symptoms gave smaller mean skin reaction sizes. The use of corticosteroids is a potential cause of depression of delayed cell-mediated immunity [36], but the basic mechanisms behind allergy and the relationship between tuberculin responses and atopic disorders are still partly unknown [37].
Infections with $M$. bovis or $M$. tuberculosis have not been detected in animals in Finland during the last 20 yrs (M.L. Katila, personal communication), but colonization or mycobacterioses caused by $M$. avium and $M$. intracellulare are relatively common in birds and pigs. This could account for the slightly higher reactivity in those children with contacts with pets or farm animals, as has also been indicated by earlier studies [12-14]. In contrast, no differences could be detected in the present study between children with contact with different species of animal or bird, as has been observed previously [12]. However, the degree of exposure may be different in an urban home from that in a rural environment, in which pets are often kept outdoors.

According to the Finnish vaccination programme, 64 children had been revaccinated against polio (Salk vaccine) during the preceding months. In these children, skin test reaction sizes were slightly but not significantly smaller than those in nonrevaccinated children. This was expected because viral disease as well as vaccination with live virus vaccines may have a depressing effect on cell-mediated immunity [36], although contradictory results after vaccination against measles, mumps and rubella have also been reported [38].

The present results also suggest that exposure to environmental mycobacteria is not very common in school-age children living in an inland lake area, and is not sufficient to maintain skin sensitivity. In addition, these results suggest that sensitization to environmental mycobacteria, known to be boosted by cross-reactive BCG vaccination, may widely vary according to geographical location even in a homogenous child population or may significantly be influenced by the BCG vaccine preparation used.

Tuberculosis is a rarely encountered disease in Finland $[1,2]$, and the need for routine bacile Calmette-Guérin vaccination at birth is being re-evaluated. As there is evidence that bacille Calmette-Guérin vaccination offers protection to children, not only against $M$. tuberculosis but also against mycobacterioses due to environmental mycobacteria $[6,10]$, changes in bacile Calmette-Guérin vaccination policy may also influence the epidemiology of disease caused by other mycobacteria.

\footnotetext{
Acknowledgements. S. Saario and P. Tamminen are acknowledged for performing the skin tests.
}

\section{References}

1. Communicable Diseases in Finland in 1996. National Public Health Institute Publications B4/1997.

2. Tala-Heikkilä M, Tuominen J, Tala E. Bacillus CalmetteGuerin revaccination questionable with low tuberculosis incidence. Am J Respir Crit Care Med 1998; 157: 1324 1327.

3. Härö AS. Tuberculosis in Finland. Dark past - promising future. Tuberc Respir Dis Yearbook 1998; 24: 1-151.

4. Hsu KHK. Atypical mycobacterial infections in children. Rev Infect Dis 1981; 3: 1075-1080.

5. O'Brien RJ, Geiter LJ, Snider DE. The epidemiology of nontuberculous mycobacterial diseases in the United States: results from a national survey. Am Rev Respir Dis 1987; 135: 1007-1014. 
6. Romanus V. The impact of BCG vaccination on mycobacterial disease among children born in Sweden between 1969 and 1993. Dissertation, Karolinska Institutet \& Smittskyddsinstitutet, Stockholm 1995.

7. von Reyn CF, Waddell RD, Eaton T, et al. Isolation of Mycobactenum avium complex from water in United States, Finland, Zaire and Kenya. J Clin Microbiol 1993; 31: 3227-3230.

8. Bleiker MA, Misljenovic O. Specific and non-specifc tuberculin sensitivity sensitivity in schoolchildren in the city of Delft - the Netherlands. Bull Int Union Tuberc Lung Dis 1986; 61: 86-87.

9. Bulow K, Piitulainen E, Kalen N, Wallin-Nilsson G, Sjögren I. Non-tuberculous mycobacterial infection - a major cause of tuberculin conversion in unvaccinated children in south Sweden. Bull Int Union Tuberc Lung Dis 1980; 55: 100-104.

10. Katila ML, Brander E, Backman A. Neonatal BCG-vaccination and mycobacterial cervical adenitis in childhood. Tubercle 1987; 68: 291-296.

11. Margileth AM. Cervical adenitis. Pediatr Rev 1985; 7: 13-24.

12. Larsson LO, Skoogh BE, Bentzon MW, et al. Sensitivity to sensitins and tuberculin in Swedish children. II. A study of preschool children. Tubercle 1991; 72: 37-42.

13. Larsson LO, Bentzon MW, Lind A, et al. Sensitivity to sensitins and tuberculin in Swedish children. Part 5. A study of school children in an inland rural area. Tubercle Lung Dis 1993; 74: 371-376.

14. Lind A, Bentzon MW, Doshee IM, et al. Sensitivity to tuberculin and sensitins in Swedish children. Bull Int Union Tuberc Lung Dis 1988; 63: 19-22.

15. Kröger L, Katila ML, Korppi M, Brander E, Pietikäinen M. Rapid decrease in tuberculin skin test reactivity at preschool age after newborn vaccination. Acta Paediatr 1992; 81: 678-681.

16. Kröger L, Katila ML, Korppi M, Pietikäinen M. Skin test reactivity to atypical mycobacteria among healthy Finnish preschool children vaccinated with BCG vaccine at birth. Acta Paediatr 1992; 81: 891-895.

17. Uotila K. Reactions to tuberculin and to vaccination in BCG-vaccinated children and youths. Bull Int Union Tuberc 1985; 60: 157.

18. Tala-Heikkilä M, Nurmela T, Misljenovic O, Bleiker MA, Tala E. Sensitivity to PPD tuberculin and M scrofulaceum sensitin in schoolchildren BCG vaccinated at birth. Tubercle Lung Dis 1992; 73: 87-93.

19. Osman AA, Hakim JK, Luneborg-Nielsen $\mathrm{M}$, et al. Comparative skin testing with PPD tuberculin, Mycobacterium avium and M. scrofulaceum sensitin in schoolchildren in Saudi Arabia. Tubercle Lung Dis 1994; 75: 38-43.

20. Stanford JL. Immunologically important constituents of mycobacteria: Antigens. In: Ratledge C, Stanford JL, editors. The Biology of Mycobacteria vol 2. London, Academic Press Ltd, 1983; 85-127.
21. "WHO standard tuberculin test". O/TB/Techn. Guide 3, 1963.

22. Goslee S, Wolinsky E. Water as a source of potentially pathogenic mycobacteria. Am Rev Respir Dis 1976; 113: 287-292.

23. Horwitz $\mathrm{O}$, Bunch-Christensen. Correlation between tuberculin sensitivity after 2 months and 5 years among BCG vaccinated subjects. Bull World Health Organ 1972; 47: $49-58$.

24. Ildirim I, Sapan N, Cavusogly B. Comparison of BCG vaccination at birth and at third month of life. Arch Dis Child 1992; 67: 80-82.

25. Karalliede S, Katugaha LP, Uragoda CG. Tuberculin response in children after BCG vaccination at birth. Tubercle 1987; 68: 33-38.

26. Kröger L, Brander E, Korppi M, et al. Osteitis after newborn vaccination with three different Bacillus Calmette-Guerin vaccines: twenty-nine years of experience. Pediatr Infect Dis $J$ 1994; 13: 113-116.

27. Iivanainen EK, Martikainen PJ, Väänänen PK, Katila ML. Environmental factors affecting the occurrence of mycobacteria in brook waters. Appl Environ Microbiol 1993; 59: 398-404.

28. Bjerkedal T. Mycobacterial infections in Norway: a preliminary note on determining their identity and frequency. Am J Epid 1966; 85: 157-173.

29. Dascalopoulos GA, Loukas S, Constantopoulos SH. Wide geographic variations of sensitivity to MOTT sensitins in Greece. Eur Respir J 1995; 5: 715-717.

30. Kim SJ, Hong YP, Bai GH, Lee EK, Lew WJ. Tuberculin PPD RT23: has it lost some of its potency. Int $J$ Tuberc Lung Dis 1998; 2: 857-860.

31. Gomstock GW. Identification of an effective vaccine against tuberculosis. Am Rev Respir Dis 1988; 138: 479 480.

32. Fine PEM. Vaccines, genes and trials. Novartis Found Symp 1999; 217: 57-72.

33. Remes S. Epidemiology of asthma and allergy at school age. Doctoral thesis. Kuopio University Publication D. Medical Sciences 141. Kuopio, 1998.

34. Shirakawa T, Enomoto T, Shimazu S, Hopkin JM. The inverse association between tuberculin responses and atopic disorder. Science 1997; 275: 77-79.

35. Alm JS, Lilja G, Pershagen G, Scheynius A. Early BCG vaccination and development of atopy. Lancet 1997; 350: 400-403.

36. Lefford MJ. Immune Response to Mycobacteria. In: Rose NR, Friedman H, Fahey JL, eds. Manual of Clinical Laboratory Immunology. 3rd Edn. Washington DC, Am Soc for Microbiol, 1988; pp. 415-421.

37. Martinati LC, Boner AL. The inverse relationship between tuberculin responses and atopic responses. Allergy 997; 52: 1036-1037.

38. Kroger L. Influence of MPR revaccination on tuberculin and sensitin skin reactions in children. Acta Paediatr 1994; 83: 232-234. 